\title{
LESSON LEARNED FROM AN EXPERIENCE OF TEACHING SUPPORT IN HIGHER EDUCATION FOR A DIGITAL TRANSITION IN THE NEW SCENARIO CREATED BY COVID-19
}

\author{
Barbara Bruschi ${ }^{1}$, Francesco Floris ${ }^{2}$, Marina Marchisio ${ }^{2}$ and Matteo Sacchet ${ }^{2}$ \\ ${ }^{1}$ Department of Philosophy and Education Sciences, University of Turin \\ Via Sant'Ottavio 20, 10124 Turin, Italy \\ ${ }^{2}$ Department of Molecular Biotechnology and Health Science, University of Turin \\ Via Nizza 52, 10126 Turin, Italy
}

\begin{abstract}
Teaching skills are fundamental for academic positions, which combine research and teaching activities. Thus, universities should look for candidates with excellent research records and teaching experience or skills; another strategy is the training of teaching staff. On the other hand, when dealing with already in-service teachers, the challenges for universities are completely different and it is often difficult to cope with digital technologies for education. Moreover, roles in the education process assume different perspectives. This is the background of this research, which investigates the measures adopted at the University of Turin to deal with the scenario of the Covid-19 pandemic and subsequent periods. 30 young graduates halfway between students and teachers, one per university department, support teachers and the digital transition. Their role ranges from the didactical support (online teaching methodologies and the use of the Learning Management System) to the preparation, delivery, and monitoring of online assessment and exams. These young assistants received a grant for their role and proper training over all these topics and other themes related to online education, such as accessibility, copyright, video editing. At the start of the second semester, a questionnaire was delivered to these grant holders to receive feedback on their activity during the first semester and exam period. We collected 26 answers from the questionnaire. Results show that, among the different roles, they were more involved with online examinations and students' support, while collaborating more with professors and with their peers. Most of these grant holders would like to participate again in such an experience, it being useful for their future career, the teachers of the future.
\end{abstract}

\section{KEYWORDS}

Digital Education, Digital Transition, Higher Education, Teacher Support, Young Assistants

\section{INTRODUCTION}

As the Covid-19 pandemic was spreading all over the world, local governments took many actions to shut down schools, colleges, and universities, leaving a lot of uncertainties about the future openings. This caused a challenge to the higher education landscape at a magnitude that had probably never been seen before. Online teaching suddenly became the only possible way to keep students engaged in these difficult times. However, this transition to online teaching requires digital technologies to be accessible to every student and teacher, but it is quite clear that it is not the case, even in the most developed countries. Besides this lack of equity in accessing digital devices and education, it soon became necessary to rethink, renovate and redesign the education systems according to the new needs. It is not just a matter of policies and interventions: the discussion must involve all the stakeholders. Teachers, the first line facing disruptive change, require an increasingly larger set of competencies, their digital competencies. This is true at all levels of education. Many works in the literature explain and assess frameworks of digital competencies for educators. Even before the Covid-19 pandemic, there was a lot of work in this sense, because of the rapidly changing scenario in a world where digital technologies are ubiquitous. This is the case of DigCompEdu (Redecker, 2016), which provides a description of the various sets of teachers' competencies for online teaching. This framework is valid for educators both at secondary schools (Fissore et al., 2020) and in higher education. Moreover, the framework 
aims at guiding policies, implementing regional and national tools and training programs, providing a common soil to help the dialogue and exchange of practices.

This work analyses the experience of teaching support in this new scenario reshaped by Covid-19 at the University of Turin. In line with the recommendations in (UNESCO-IESALC, 2020) to anticipate the possibility of closed institutions, the university introduced 30 new figures to facilitate the transition from traditional to digital education, giving didactical and technical support and helping in the preparation, delivery, and monitoring of online assessment and exams - this last item being one of the main challenges. These grant holders received proper training on all topics and themes related to online and digital education. Training topics are Instructional Design, accessibility, copyright, video editing, usage of the Learning Management System. At the start of the second semester of the academic year 2020/2021, a questionnaire was delivered to these grant holders to receive feedback on their activity during the first semester and the exam period. We collected 26 answers from the questionnaire: almost all grant holders responded. Results show that the experience was positive, with a strong collaboration with professors and with their peers.

The paper is divided into sections as follows. Section 2 describes the state of the art. Section 3 describes the support that was designed and delivered at the University of Turin. Section 4 introduces the research questions and the related methodology. Section 5 presents and discusses the results of this experience.

\section{STATE OF THE ART}

The perception of education can differ between students and teachers. In (Asikainen et al., 2018) the authors asked Likert-scale and an open-ended question to 68 teachers and 104 students with results that showed significant differences in both students' and teachers' experiences. Teachers experience the support given to students more positively than the students do. In addition, teachers experience the commonality and interaction between teachers and students more positively than the students do. Institutional leaders should pay more attention to the teacher-student relationship at the higher education level, emphasizing abilities to interact with others and social behavior when recruiting staff.

Digital tools support teaching in higher education in a pervasive way. These tools demand new responsibilities on the teacher and influence teacher roles. This has been well known since the first years of the new millennium. In (Wake et al., 2007), the authors investigated a case study about the introduction of a digital tool, which had become fully integrated with the teaching-learning environment, and they highlighted the birth of new teacher roles, one of the most crucial changes being the move from private to public feedback. The study was conducted through interviews and the study of textual artifacts. The use of digital technologies alone does not result in improved educational outcomes and ways of working (Kirkwood, 2009). Students' engagement with e-learning relates to their expectations and conceptions of learning and to assessment demands. Academics need to re-assess their own beliefs and practices concerning teaching and assessment and their impact on the experience of learners. Digitalization in Higher Education institutions does not only concern teachers, but also many educational stakeholders. Digital skills are becoming increasingly relevant in the workplace, especially in education. One of the main objectives for universities is training current and future teachers together with professionals and academic staff. Different countries and institutions proposed policies, initiatives, and strategies. In Germany, researchers at the University of Oldenburg found that both teachers and students use a limited number of digital technology for predominantly assimilative tasks, with the Learning Management System being perceived as the most useful tool (Bond et al., 2018). They based their analysis on two datasets regarding the use and perceptions of students $(n=200)$ and teachers $(n=381)$ on the use of digital tools.

Covid-19 pandemic disruptively changes students' perception regarding online learning. From a study conducted in two of the largest Romanian universities (Coman et al., 2020), the authors revealed that higher education institutions were not prepared for exclusively online learning. When unprepared, the disadvantages of online learning become more prominent. Technical issues were found to be the most important ones, followed by teachers' lack of technical skills and their teaching style improperly adapted to the online environment, up to the lack of interaction with teachers or poor communication with them. 
Several programs arose to face such emergency. In (Quezada et al., 2020), the authors discusses how the pandemic created opportunities for their department, students, teachers, school district partner teachers, faculty, and university supervisors to be "changemakers" in the transition from an on-campus face to face teaching and on-school site supervision to remote teaching and supervision of practicum and student teachers. Their program yielded some themes: Technology-Based Instructional Strategies, Technology-Based Support Office Consultation, Alternative Technology-Based Course Assessments, Feedback for Learning and Teaching Improvement, and Social-Emotional Engagement in Courses, and Support of Clinical Placement. The result after a transition week was the Instructional Plan of Action (IPA) to support all full-time and adjunct instructional needs and teacher candidates.

Emotion and mental strength played a role, too. Teachers were strongly affected by the pandemic, and (Pressley, 2021) gained insight into the impact and the factors that lead to teacher anxiety and burnout.

There is research about teacher support in secondary education (Fissore et al., 2020) and in higher education (Floris et al., 2020), but there is also research about teaching and learning practices, see (Carrillo \& Flores, 2020) for a review. In particular, there are practice involving Students as Partners in Higher Education. Students can be partners in different aspects, in governance, pedagogy, inclusion. In (Bovill, 2017), the author proposes a participation matrix, a way to be transparent about the different roles of different actors at different stages in the partnership between teachers and students. The teacher should lead the initiative at the start, but at later stages, the teacher is working in partnership with different subsets of the student cohort. A range of challenges arises in this context: establishing and maintaining partnerships, limited contact with students, the large size of many university classes, student or staff skepticism about partnership.

Guidelines for facing challenges in educations appear in (Digital Education Action Plan 2021-2027), which outlines the European Commission's vision for high-quality, inclusive, and accessible digital education in Europe. Its aim is to learn from the COVID-19 crisis and adapt education and training systems to the digital age. Researchers from all over Europe participated to open public consultations on the new action plan from June to September 2020.

At the University of Turn in Italy, the Covid-19 pandemic affected the second semester of the academic year 2019/2020 and the academic year 2020/2021. In the first case, the response was due to the emergency, online teaching was not planned at all and professors had to face the situation with their previous knowledge or work with online learning (Bruschi et al., 2020). In the second case, all stakeholders knew that the new academic year would be a new scenario for higher education generated by the pandemic. The situation has been constantly evolving, and the first period of the academic year was still characterized by a health emergency, but it is now clear that new ways of teaching and learning are opening up. All teachers and students must be prepared.

\section{SUPPORT FOR DISTANCE TEACHING}

To guarantee permanent support to teachers, which is a trend research theme, the university introduced 30 young figures, young graduates halfway between a student and a professor. They received a grant for their activity as assistants. The choice of young graduates resides in the proximity with students, thanks to a smaller age gap; moreover, it is easier to recruit young graduates than other kinds of teaching assistants, for which competition is required. These grant holders got their workplace inside the staff members of all departments of the university: there are 27 departments at the University of Turin, so one grant holder per department, the residual ones were hired in Interdepartmental centers. Their role is to spread digital education competencies to all areas. Thus, the number of teachers they supported is quite variable, depending on the size of the department. Requirements for a successful application were the knowledge of a specific discipline, the main one of each department, even though disciplines can differ greatly within a department. Because of this, the collaboration between the grant holders was highly encouraged. No particular mastery in teaching was required because these grant holders were trained (online, see Figure 1 for an overview of the online training course) on the various aspects related to their future activity and online teaching. First, they were introduced to the situation at the university and the importance of their role, with an overview of the set of recommendations and university policies for the emergency. They also received proper professional training on online teaching methodologies, how to use the Learning Management System integrated adopted by the University of Turin, how to prepare, deliver and monitor online assessment, how to edit videos, and other topics related to online 
education, like accessibility and copyright. The training program was carried out following positive previous experiences in training those who will be trainers (Marchisio et al., 2019) especially in the case of open online courses inside the start@unito experience (Bruschi et al., 2021; Marchisio et al., 2020).

\section{RESEARCH QUESTION AND METHODOLOGY}

The research question that defines the research described in this work is: how can a university support its teaching staff in the transition to digital education, especially in new normal scenarios like the ones arisen during the Covid-19 pandemic?

To answer this question, many focus groups took place to collect needs and specific requests and, at the start of the second semester, a questionnaire was delivered to these grant holders to receive feedback on their activity during the first semester and exam period. The questionnaire is composed of different questions about their perspective, the activities they performed, the usefulness of the training, the importance of this experience for their future job applications. We collected 26 answers from the questionnaire of grant holders hired in 23 different departments. Some qualitative remarks from focus groups with the deputy directors for teaching and the grant holders themselves are reported in the last lines of the results section.

\section{Support to remote teaching 2020/2021}
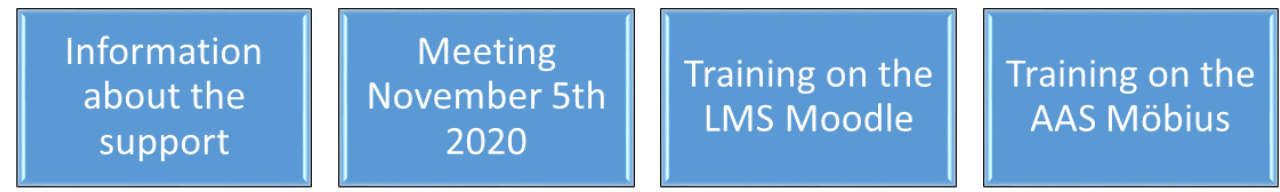

Training on

Accessibility and Copyright
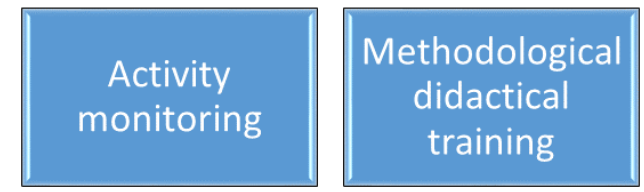

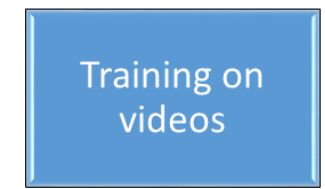

Figure 1. An overview of the training course for grant holders

\section{RESULTS}

After the training, the grant holders were active resources for their departments, under the supervision of the Department Directors and in collaboration with the local staff. Thus, the first aspect that was thoroughly investigated is the kind of activity they performed. As depicted in Table 1, the main areas of intervention involved supporting online examinations and responding to students' requests (median 4 over a 5-point scale). This is mainly due to the large-scale online examination (the University of Turin has more than 80 thousand students) and to the unavoidable disorientation of first-year students (around 26 thousand students). Since grant holders are familiar with content topics, they were sometimes requested to check online contents and modules and to develop materials and assessments. They were less involved in the design phase or with video making because grant holders arrived after a possible design phase and most of the lessons were carried out through video conferencing systems. They covered also other important activities:

- Review of the web pages of the degree programs, to keep the information up-to-date, also due to the changing rules caused by the Covid-19 period.

- Creation of material for university orientation, especially inside the Orient@mente university action (Barana et al., 2017a; Barana et al., 2017b), an experience of online delivery of open courses for university guidance. 
- Training meetings and contents for teachers, to spread what they learned during the training course in the departments.

- Remote exam assistance, especially in large-scale assessment for open online courses delivered by many degree programs. The role of the grant holders was checking identities, camera control, support students with basic immediate help and reassure them.

- Management of a database of all the useful material already prepared and available, to prepare a long-term repository of useful contents.

- Analysis of the results of the exams in the online session, comparing the results with the previous in-person exams.

- Questionnaires for students and teachers, to understand in their local department or degree program the implications of the Covid-19 crisis on students and to collect the needs of teachers.

Table 1. Summary of the answers to "To what extent were you involved in the following activities?" over a 5-point Likert scale, in which $1=$ a little, $5=$ a lot

\begin{tabular}{lcc}
\hline Activity & Median & IQR \\
\hline Design of online educational paths & 2 & 2 \\
Development of online contents & 3 & 2 \\
Check online contents & 3 & 2 \\
Check modules & 3 & 2.75 \\
Cataloging of online contents & 2 & 2 \\
Preparation of quizzes with automatic evaluation & 3 & 3 \\
Preparation and support in making videos & 2 & 2 \\
Support in the administration of remote examinations & 4 & 2 \\
Respond to support requests & 4 & 2 \\
\hline
\end{tabular}

Table 2. Summary of the answers to "How much did you collaborate with the following categories of people from the university?" over a 5-point Likert scale, in which $1=$ a little, $5=$ a lot

\begin{tabular}{lcc}
\hline Category & Median & IQR \\
\hline Professors & 4.5 & 1 \\
Students & 1.5 & 1 \\
Researcher & 2 & 2.75 \\
Technicians & 3 & 1 \\
Administrative staff & 3 & 2 \\
Postdoctoral researchers & 1 & 1 \\
Ph.D. & 1 & 1 \\
Other grant holders & 4 & 2 \\
\hline
\end{tabular}

Table 2 shows the main collaborations between other stakeholders inside the university. The grant holders collaborated mostly with professors, but also with other grant holders, as peer support to exchange ideas, documents, and advice. The grant holders collaborated less with researchers, postdoctoral fellows or PhDs. It is possible that they were not aware of the precise academic position of some of their collaborators. This also indicates that older professors are more in need of support for the digital transition in the new scenario, due to less familiarity with new technologies, and due to heavier institutional and research commitments. This table highlights the reciprocal support and the collaborative work with peers, which is one of the aspects that grant holders liked, as written in the open comments. Other particularly appreciated aspects are: 
- The perception of usefulness, especially due to the Covid-19 period and to the fact that most grant holders just graduated.

- The gratitude they received from teachers and staff: their work has been perceived as essential.

- Solving problems and provide solutions to teachers' difficulties.

- The chance to manage their work autonomously.

There were of course also some difficulties in their daily duties. Some grant holders highlighted the difficulty to let teachers and staff know that they were there to support and the precise definition of their competencies, which were sometimes overlapping other figures (but that is inside the meaning of support).

Concerning the training, grant holders' participation was mandatory and all of them attended most of the training sessions. Their training was made by experts in digital education and concerned the following topics:

- Accessibility and Copyright

- The Learning Management System

- Automated Assessment System

- Instructional design

- Video editing

Table 3 summarizes grant holders' evaluation of the training. The training they attended was very useful for the support that they had to provide to the departments and professors in order to improve online teaching. They stated that the training provided food for thought and gave them the necessary skills. The young age of these figures allowed them to be easily accepted by the teachers. They are aware of the potential consequences of this experience on their future career, and they think it will be useful (median 3 over a 5 -point scale). Moreover, they will gladly apply again for the same position and the same experience (median 4 over a 5 -point scale).

Table 3. Summary of the answers to "How do you rate the training received in the following areas?" over a 5-point Likert scale, in which $1=$ bad, $5=\operatorname{good}$

\begin{tabular}{lcc}
\hline Category & Median & IQR \\
\hline Usefulness & 4 & 2 \\
Relevance with the activities that you will carry out & 4 & 2 \\
Tips for reflection on the activities that you will carry out & 4 & 2 \\
Acquisition of skills & 4 & 2 \\
\hline
\end{tabular}

The topics were all interesting for grant holders, but the most appreciated one is the Learning Management System lesson. This is probably due to the strong basis that a Learning Management System gives to online learning, but also to the practical approach: grant holders had to study hands-on a local platform with more privileges than they had before, particularly interesting for new graduates and for the difficult times of pandemic. Many of the open comments state that grant holders would like to receive more training, even more personalized in their particular area.

A remark that was given by some grant holders concerns their role in the department. In some cases, it was difficult and not clear. Difficult due to established ways of teaching and to the waving amount of work, heavy during classes and exams, relaxed in other periods. Not clear due to the different needs of each department and sometimes to the lack of communications and collaboration between grant holders and teachers, staff, and different offices. Nonetheless, most of the grant holders stated that they would like to repeat the same experience $(85 \%)$ and that it was very useful or quite useful for their future career $(85 \%)$.

A final source of feedback about the work of the grant holders comes from focus groups with the deputy directors for teaching, whose role in this field was to manage the grant holders, and with the grant holders themselves. From the first ones, it emerged that grant holders were proactive in their job and delicate with students. They worked on the inclusiveness of online materials and they organized the materials for the remote lessons to make them more usable. Mapping the online materials available to students was another of their duties, so as to intervene when there is a shortage. Grant holders created question archives for remote exams. From the second kind of focus groups with the grant holders, it emerged that they collaborated between fellows from different departments and had many personal appointments with teachers, both for basic and specific requests, in the evening, too, and at times outside the hours of lessons or research or assistance in the departments. Their feedback on teachers was positive; they noted an increase in the autonomy of teachers to prepare materials, such as tests. They would have liked even more training to be able to propose new solutions. 


\section{CONCLUSION}

The analysis of the responses given by grant holders to the questionnaires helps us answer the research question. This is a good starting point to help a higher education institution in facing the challenges of teachers' support and digital transition. The investment made by the university in the recruitment of people dedicated to supporting online teaching and teachers has certainly been a positive experience. One lesson learned from this experience is that such an immediate support is effective because it can be deployed very quickly. Moreover, second lesson learned, a young graduate is easier to train and facilitates the relationship with the teacher. Third lesson learned, this action works on both the two priority areas of the Digital Education Action Plan: grant holders helped in producing content and developing digital skills, together with enhancing and strengthening the digital skills of teachers useful in distance learning, these skills are useful for switching to online teaching. Methodologies combined with new technologies make it possible to adopt new teaching models to respond to open scenarios.

The hurry caused by the Covid-19 pandemic made it difficult to carefully plan all the phases of the intervention. It presented some difficulties in the organization and management of activities since everything took place remotely, with natural implications in communications. Despite this, in addition to facing the academic year more effectively in an uncertain setting, the experience represents a first response to the need for permanent and transversal support for teachers to offer quality and up-to-date teaching in new scenarios. This is not just a response to an emergency, but it is also aimed at spreading innovative methodologies and technologies to university teachers. Another positive effect is the temporary employment of newly graduated people, which could have trouble in finding suitable job opportunities in a time when traveling and interviews are restricted.

Beyond the activities described in this research, other parallel actions are necessary. All this work should be accompanied by an action dedicated to strengthening the infrastructure and it requires the engagement at institution level. Future activities concern a more structured way to face new scenario. The main action that is underway is the introduction of a Teaching and Learning Center to enhance didactics in higher education, hosting permanent figures that can support teachers. Permanent roles are necessary because the transition to the new scenario takes more than one academic year. Other future activities concern the creation of a good internal quality monitoring system, the eventual design and execution of a second round of grant holders for the next academic year, together with a new assessment of this kind of support at the end of the grant.

\section{REFERENCES}

Asikainen, H., Blomster, J., Virtanen, V. (2018). From functioning communality to hostile behaviour: students' and teachers' experiences of the teacher-student relationship in the academic community, Journal of Further and Higher Education, 42:5, 633-648, https://doi.org/10.1080/0309877X.2017.1302566

Barana, A., Bogino, A., Fioravera, M., Floris, F., Marchisio, M., Operti, L., Rabellino, S. (2017a). Self-paced approach in synergistic model for supporting and testing students: The transition from Secondary School to University. Proceedings of 2017 IEEE 41st Annual Computer Software and Applications Conference (COMPSAC), 404-409, IEEE 2017. https://doi.org/10.1109/COMPSAC.2017.211

Barana, A., Bogino, A., Fioravera, M., Marchisio, M., Rabellino, S. (2017b). Open Platform of Self-paced MOOCs for the continual improvement of Academic Guidance and Knowledge Strengthening in Tertiary Education. Journal of E-Learning and Knowledge Society, 13(3). https://doi.org/10.20368/1971-8829/1383

Bond, M., Marín, V.I., Dolch, C. et al. (2018). Digital transformation in German higher education: student and teacher perceptions and usage of digital media. Int $J$ Educ Technol High Educ 15, 48. https://doi.org/10.1186/s41239-018-0130-1

Bovill, C. (2017). A Framework to Explore Roles Within Student-Staff Partnerships in Higher Education: Which Students Are Partners, When, and in What Ways?, International Journal for Students as Partners, 1 (1).

Bruschi, B., Marchisio, M., Sacchet, M. (2021) Online Teaching in Higher Education with the Support of Start@Unito During Covid-19 Pandemic. In: Agrati L.S. et al. (eds) Bridges and Mediation in Higher Distance Education. HELMeTO 2020. Communications in Computer and Information Science, vol 1344. Springer, Cham. https://doi.org/10.1007/978-3-030-67435-9_15

Carrillo, C., Flores, M. A. (2020) COVID-19 and teacher education: a literature review of online teaching and learning practices, European Journal ofTeacher Education, 43:4, pp. 466-487. https://doi.org/10.1080/02619768.2020.1821184 
Coman, C, Țîru, L. G., Meseșan-Schmitz, L., Stanciu, C., Bularca, M. C. (2020). Online Teaching and Learning in Higher Education during the Coronavirus Pandemic: Students' Perspective, Sustainability 12, no. 24: 10367. https://doi.org/10.3390/su122410367

Communication From The Commission To The European Parliament, The Council, The European Economic And Social Committee And The Committee Of The Regions Digital Education Action Plan 2021-2027 Resetting education and training for the digital age. COM/2020/624 final. Retrieved from https://eur-lex.europa.eu/legalcontent/EN/TXT/?uri=CELEX:52020DC0624, last accessed 2021/05/31.

Fissore, C., Floris, F., Marchisio, M., Rabellino, S., Sacchet, M. (2020). Digital competences for educators in the Italian secondary school: a comparison between DigCompEdu reference framework and the PP\&S project experience, MCCSIS2020 - Proceedings of International Conference on e-Learning 2020 (EL2020), pp. 47-54. http://dx.doi.org/10.33965/el2020_202007L006

Fissore, C., Marchisio, M., Rabellino, S. (2020). Secondary School Teacher Support and Training for Online Teaching during the COVID-19 Pandemic, European Distance and E-Learning Network (EDEN) Conference Proceedings, In EDEN Conference Proceedings, No. 1, pp. 311-320.

Floris, F., Genovese, A., Marchisio, M., Roman, F., Sacchet, M. (2020). Teacher support in COVID-19 pandemic to develop blended learning disruptive models in higher education. Paper presented at the 17th International Conference on Cognition and Exploratory Learning in Digital Age, CELDA 2020, pp. 173-180.

Kirkwood, A. (2009). E-learning: you don't always get what you hope for, Technology, Pedagogy and Education, 18:2, pp. 107-121, https://doi.org/10.1080/14759390902992576

Marchisio, M., Rabellino, S., Sacchet, M. (2020). Start@ unito as Open Educational Practice in Higher Education. Journal of E-Learning and Knowledge Society, 16(4), 46-55. https://doi.org/10.20368/1971-8829/1135354

Marchisio, M., Sacchet, M., Salusso, D. Instructional Design to "Train the Trainers": The Start@unito Project at the University of Turin, Multi Conference on Computer Science and Information Systems, MCCSIS2019 - Proceedings of the International Conference on e-Learning 2019 (EL2019), pp. 195-202. https://doi.org/10.33965/el2019_201909F025

Pressley, T. (2021). Factors Contributing to Teacher Burnout During COVID-19. Educational Researcher, 50(5), pp. 325-327. https://doi.org/10.3102/0013189X211004138

Quezada, R. L., Talbot, C., Quezada-Parker, K. B. (2020) From Bricks and Mortar to Remote Teaching: A Teacher EducationProgram's Response to COVID-19, Journal of Education for Teaching, 46:4, pp. 472-483. https://doi.org/10.1080/02607476.2020.1801330

Redecker, C. (2017). European Framework for the Digital Competence of Educators: DigCompEdu. Punie, Y. (ed). EUR 28775 EN. Publications Office of the European Union, Luxembourg, https://doi.org/10.2760/159770

UNESCO-IESALC: Coronavirus COVID-19 and Higher Education: Impact and Recom-mendations, https://www.iesalc.unesco.org/en/2020/03/09/coronavirus-covid-19-and-higher-education-impact-andrecommendations/, last accessed 2021/04/06.

Wake, J. D., Dysthe, O., Mjelstad, S. (2007). New and Changing Teacher Roles in Higher Education in a Digital Age. Educational Technology \& Society, 10 (1), 40-51. 